\title{
Total diz protezi sonrası gelişen enfeksiyonlarda alınacak önlemler, tanı ve tedavi yöntemleri
}

\author{
Prevention, diagnosis and treatment methods \\ of infections after total knee arthroplasty
}

\author{
Kadir Uzel, İbrahim Azboy \\ İstanbul Medipol Üniversitesi Tıp Fakültesi, Ortopedi ve Travmatoloji Ana Bilim Dalı, İstanbul
}

\begin{abstract}
Total diz protez enfeksiyonları, total diz protezi ameliyatları sonrası hastaya, hekime ve sağlık sistemine ciddi yükler getiren tedavisi en zor komplikasyonlardan biridir. Total diz protezi sonrası gelişen enfeksiyonların tanı ve tedavisi ile ilgili zorluklar, hasta sağlığı ve ülke ekonomilerine maliyeti göz önünde bulundurulduğunda, enfeksiyon gelişiminin önlenmesi daha akılı bir yaklaşım olacaktır. Bu amaçla hastaya ait risk faktörlerinin belirlenerek bu risk faktörleri ameliyat öncesi dönemde yeterli ve özenli bir şekilde optimize edilmelidir. Ameliyathane ortamının standartlara uygun olması, cerrahinin titiz yapılması, yumuşak doku hasarından kaçınılması ve ameliyat sonrası yara komplikasyonlarının etkili tedavisi de total diz protezi sonrası enfeksiyon gelişiminin önlenmesinde önemli rol oynamaktadır. Total diz protezi sonrası enfeksiyon geliştiğinde ise vakit kaybetmeden doğru tanı konmalı ve hastaya en uygun tedavi yöntemi belirlenerek uygulanmalıdır. Uygun tedavi yaklaşımının belirlenmesinde; hastanın yaşı, semptomların ortaya çıkış süresi, eşlik eden hastalıkları, kemik kalitesi, yumuşak doku örtüsünün durumu ve mikroorganizma tipi göz önünde bulundurulmalıdır. Bu derlemede, güncel bilgiler ışığında, total diz protezi sonrası enfeksiyon gelişiminde etkili olan risk faktörleri, enfeksiyondan korunma yöntemleri ve enfeksiyon gelişen hastaların uygun tanı ve tedavi yöntemleri ile yönetimi ele alınmıştır.

Anahtar sözcükler: diz; total diz protezi; periprostetik enfeksiyon; risk faktörleri
\end{abstract}

\begin{abstract}
Total knee arthroplasty infections are one of the most difficult complications to treat after total knee arthroplasty which imposes serious burdens on the patient, physician and health system. Considering the difficulties related to the diagnosis and treatment of total knee arthroplasty infection, patient health and economic reasons, prevention of infection rather than treatment would be a more appropriate approach. Prevention should begin with the identification of the risk factors of the patient, and the existing risk factors should be optimized adequately and carefully in the preoperative period. The compliance of the operating room to the standards, meticulous surgery, avoidance of soft tissue damage and effective treatment of postoperative wound complications also play a significant role in preventing total knee arthroplasty infection. Once total knee arthroplasty infection occurs, the correct diagnosis should be made immediately and the most appropriate treatment method for the patient should be determined and applied. While determining the appropriate treatment approach; age, duration of symptoms, comorbidities, bone quality, soft tissue coverage and type of microorganism should be considered. In this review, risk factors for periprosthetic infection, prevention methods and treatment methods applied after infection is discussed based on current information.
\end{abstract}

Key words: knee; total knee arthroplasty; periprosthetic infection; risk factors

Total diz protez enfeksiyonu, total diz protezi sonrası en çok korkulan ve tedavisi en zor komplikasyonlardan biridir. Total diz protez enfeksiyonu, primer TDP sonrası \%0,8-\%1,9 oranında görülmektedir. ${ }^{[5]}$ Ancak diz protezi revizyonunun en sık nedenin total diz protez enfeksiyonu olduğu bildirilmiştir. ${ }^{[5,6]}$

\section{RISK FAKTÖRLERI VE KORUNMA}

Total diz protezi enfeksiyonu tedavisinin zorluğu göz önüne alındığında enfeksiyondan korunma

İletişim / Contact: Prof. Dr. İbrahim Azboy • E-posta / E-mail: ibrahimazboy@gmail.com

ORCID iD: Kadir Uzel, 0000-0002-3695-9884 • ibrahim Azboy, 0000-0003-0926-3029

Geliş / Received: 13 Temmuz 2021 • Kabul / Accepted: 24 Temmuz 2021 
akılı bir yaklaşım olacaktır. Bu nedenle hastaya ait risk faktörlerinin azaltılması, ameliyathane ortamının standartlara uygun olması ve ameliyat sonrası yara komplikasyonlarının etkili tedavisi önemli rol oynamaktadır.

Diyabet, obezite, romatoid artrit, steroid kullanım öyküsü, sigara kullanımı, malnütrisyon, malignite, revizyon cerrahisi, daha önce protez cerrahisi ve septik artrit geçirme öyküsü, anemi, pulmoner, kardiyovasküler ve renal yetmezlik öyküsü hastaya ait önemli risk faktörleri olarak tanımlanmıştır. ${ }^{[7,8]}$ Bu risk faktörlerinin dikkatli bir şekilde değerlendirilerek mümkün olan durumların düzeltilmesi için gayret gösterilmeli ve hasta ameliyata mümkün olan en uygun şartlarda alınmalıdır.

Diyabetik hastalarda ameliyat öncesi dönemde kan şekerinin $200 \mathrm{mg} / \mathrm{dl}$ 'nin ve HbA1C düzeyinin \%8'in altında olması TDP enfeksiyon riskini azaltmaktadır. ${ }^{9,10]}$ Vücut kitle indeksi $30 \mathrm{~kg} / \mathrm{m}^{2}$ nin üzerinde olan obez hastalarda TDP sonrası enfeksiyon riski anlamlı derecede artmaktadır. Vücut kitle indeksi $35 \mathrm{~kg} / \mathrm{m}^{2}$ 'nin üzerinde olan hastalarda TDP sonrası enfeksiyon riskinin 6,7 kat arttığı belirtilmiştir. ${ }^{[8,11]}$

Romatolojik hastalıkları olan hastalar hem hastalığın doğası gereği hem de hastalık nedeni ile kullanılan immunosupresif ilaçlardan dolayı TDP sonrası enfeksiyon gelişimi açısından riskli gruptadırlar. ${ }^{[12]}$ Ameliyat öncesi dönemde hastalık modifiye edici ajanların uygun zamanda kesilmesi veya doz ayarlaması yapılarak TDP sonrası enfeksiyon riski azaltılabilir. ${ }^{[13]}$

Sigara vazokonstrüksiyona neden olarak yara bölgesine oksijen transportunu bozup, yara iyileşmesini olumsuz yönde etkiler. Enfeksiyon riskini azaltmak için protez ameliyatından 6-8 hafta önce sigaranın bırakılması önerilmektedir. ${ }^{[14]}$

Malnütrisyon, kollajen sentezini bozarak ve bağışıklık sisteminin çalışmasını olumsuz yönde etkileyerek enfeksiyon riskini artırır. ${ }^{[15]}$ Serum albümin değerinin $3,5 \mathrm{gr} / \mathrm{dl}$, lenfosit sayısının $1500 / \mathrm{ml}$ ve transferin düzeyinin $200 \mathrm{mg} / \mathrm{dl}$ 'nin altında olduğu hastalarda yara enfeksiyon riski artmaktadır. ${ }^{[14,15]}$ Bu nedenle malnütrisyonu olan hastalar ameliyat öncesi bir beslenme uzmanına danışılmalıdır.

Ameliyat öncesi dönemde hemoglobin düzeyinin erkeklerde $13 \mathrm{~g} / \mathrm{dl}$ ve kadınlarda $12 \mathrm{~g} / \mathrm{dl}$ 'nin altında olduğu durumlarda anemi nedenin araştırılması ve hemoglobin düzeyleri istenen düzeye getirildikten sonra hastanın cerrahiye alınması enfeksiyon riskini azaltacaktır. ${ }^{[16]}$ Dizüri, noktüri ve inkontinans gibi semptomları olan hastalarda idrar tetkiki ve kültürü yapılarak idrar yolu enfeksiyonun tedavi edilerek hastanın ameliyata alınması önerilmektedir ${ }^{[16]}$ Ağız hijyeni bozuk olan, sigara kullanan ve son bir yıl içinde diş hekimi kontrolüne gitmemiş olan hastaların diş hekimine konsülte edilmesi ve gerekli tedaviler yapıldıktan sonra ameliyat edilmeleri uygun bir yaklaşım olacaktır. ${ }^{[17]}$

Son yıllarda yapılan çalışmalarda D-vitamini seviyesinin düşük olmasının TDP enfeksiyon riskini artırdığı bildirmiştir. ${ }^{[18,19]} \mathrm{Bu}$ nedenle ameliyat öncesinde D-vitamini eksikliğinin düzeltilmesi önerilmektedir. ${ }^{[19]}$

Cilt temizliği ameliyat öncesinde önemli basamaklardan biridir. Ameliyat bölgesinin temizlenmesine ek olarak hastalara ameliyat öncesindeki akşam veya ameliyat sabahı klorheksidin ile tüm vücut banyosu yapilması tavsiye edilmelidir. ${ }^{[16]}$

Total diz protezi enfeksiyonlarından korunmada en önemli basamaklardan biri de antibiyotik profilaksisi uygulanmasıdır. Enfeksiyona en sık neden olan ajanlar stafilokokkus aureus ve stafilokokkus epidermidis olduğundan sefazolin ilk seçilmesi gereken antibiyotik olmalıdır. Antibiyotikler insizyon öncesi 30-60 dakika içinde uygulanmalı ve kiloya göre doz ayarlaması yapılmalıdır. ${ }^{[20,21]}$ Metisiline dirençli stafilokokkus aureus (MRSA) taşıyıcılarında, hastanede yatmakta olan hastalarda ve hastane çalışanlarında, vankomisin veya teikoplanin bir alternatif olarak kullanılabilir. Ameliyat süresinin ilacın bir ya da iki yarı ömründen daha uzun sürmesi, ameliyat sırasında hastaya verilen intravenöz sıvının 2000 ml'den fazla olması veya kanamanın 2000 ml'den fazla olması durumunda, ek antibiyotik dozu uygulanması önerilmektedir.

Ameliyathane koşulları ve cerrahi ekipmanın sterilizasyonu da enfeksiyon açısından oldukça önemli role sahiptir. TDP enfeksiyonu oluşumunu önlemek amacıyla ameliyathane odasına giriş ve çıkışların en az seviyeye indirilmesi, temiz hava akımının sağlanması, uzun olgularda sık eldiven değiştirtilmesi, mümkün oldukça ameliyat süresinin kısaltılması ve cerrahi aletlerin uygun şekilde sterilizasyonu önemlidir. ${ }^{[22,23]}$

\section{TANI VE SINIFLANDIRMA}

Tanı yöntemleri arasında klinik seyir, serum ve sinovyal sıvı belirteçleri, mikrobiyolojik yöntemler ve radyolojik görüntüleme yöntemleri kullanılmaktadır.

Ağrı, şişlik, ısı artışı ve sinovit sık görülen bulgulardır. İlerlemiş enfeksiyonlarda fistül oluşumu ve pürülan akıntı görülebilir. ${ }^{[24]}$ Direkt grafide fokal osteoliz alanları ve periosteal yeni kemik oluşumu enfeksiyon lehine değerlendirilmelidir. C-reaktif protein düzeyi (CRP), eritrosit sedimentasyon hızı (ESH) ve D-dimer sık tercih edilen serum belirteçleridir. Klinik şüphe varlığında ve/veya serum belirteçlerinden bir veya bir kaçının yüksek olması durumunda vakit kaybetmeden eklem 
aspirasyonu yapılmalıdır. Bu işlemden en az iki hafta önce antibiyotikler kesilmiş olmalıdır. Eklem sıvısından lökosit esteraz testi yapılmalı, beyaz küre sayısı, polimorfonükleer lökosit yüzdesi belirlenmeli ve aspirasyondan hemen vakit kaybetmeden sonra pediatrik kan kültür tüplerine ekim yapmalıdır. ${ }^{[25]}$

2018 yılında Philadelphia'da gerçekleştirilen ikinci International Concensus Meeting (ICM) delegasyonu periprostetik enfeksiyon (PPE) majör tanı kriterlerinde değişikliğe gitmezken minör tanı kriterleri için puanlama sistemini önermiştir. Buna göre iki kültürde aynı etkenin üretilmesi veya protezle ilişkili sinus yolunun varlı̆̆ı majör kriterler olarak kabul edilmektedir. Minör kriterler göz önüne alındığında altı veya daha fazla puan alan hastalar enfekte olarak kabul edilirken, üç veya altındaki puanlarda enfeksiyon düşünülmemesi önerilmektedir (Tablo 1). ${ }^{[25]}$

Periprostetik eklem enfeksiyonu sınıflandırması şikâyetlerin başlangıç süresine ve ameliyattan sonra geçen zamana bağlıdır. Sınıflandırmalar aynı zamanda tedavi kararının verilmesinde de oldukça önemlidir. Tsukayama ve ark., total eklem artroplasti enfeksiyonunu dört evreye ayırarak sınıflandırmışlardır (Tablo 2). ${ }^{[26]}$

Tablo 1. İkinci International Consensus Meeting (ICM) periprostetik eklem enfeksiyon tanı kriterleri[25]

\begin{tabular}{|c|c|c|c|c|}
\hline Major kriterler (aşağıdakilerden en az birinin varlığı) & & & & Karar \\
\hline İki kültürde aynı mikroorganizmanın üremesi & & & & \multirow{2}{*}{ Enfekte } \\
\hline \multicolumn{4}{|l|}{ Eklemle ilişkili sinus varlığı veya protezin görülmesi } & \\
\hline & \multicolumn{2}{|c|}{ Eşik değer } & \multirow[b]{2}{*}{ Puan } & \multirow[b]{2}{*}{ Karar } \\
\hline Minör kriterler & Akut & Kronik & & \\
\hline $\begin{array}{l}\text { Serum CRP }(\mathrm{mg} / \mathrm{l}) \\
\text { veya }\end{array}$ & 100 & 10 & 2 & \multirow{10}{*}{$\begin{array}{l}\text { Kombine edildiğinde } \\
\geq 6 \text { Enfekte } \\
4-5 \text { Belirsiz } \\
\leq 3 \text { Enfekte değil }\end{array}$} \\
\hline D-dimer (ng/ml) & Bilinmiyor & 860 & & \\
\hline Serum sedimentasyon hızının artması (mm/saat) & Rolü yok & 30 & 1 & \\
\hline $\begin{array}{l}\text { Sinovyal beyaz küre sayısının artması }(\mathrm{ml}) \\
\text { veya }\end{array}$ & 10,000 & 3000 & 3 & \\
\hline $\begin{array}{l}\text { Lökosit esteraz testinin pozitif olması } \\
\text { veya }\end{array}$ & ++ & ++ & & \\
\hline Alfa defensin testinin pozitif olması & 1,0 & 1,0 & & \\
\hline Sinovyal PMNL (\%) & 90 & 70 & 3 & \\
\hline Tek pozitif kültür & & & 2 & \\
\hline Pozitif histoloji & & & 3 & \\
\hline İntraoperatif pürülansın pozitif olması & & & 3 & \\
\hline
\end{tabular}

Tablo 2. Tusukayama ve ark.'nın geliştirdikleri periprostetik eklem enfeksiyonu sınıflandırması ${ }^{[26]}$

\begin{tabular}{clll}
\hline Tip & Sınıflandırma & Tanı & Tedavi \\
\hline I & Cerrahi sırasında pozitif kültür & ikiden fazla pozitif kültür & Antibiyotik tedavisi \\
II & Cerrahi sonrası erken enfeksiyon & Ameliyat sonrası $<4$ haftada gelişen enfeksiyon & $\begin{array}{l}\text { Debridman, protezin korunması ve } \\
\text { antibiyotik tedavisi }\end{array}$ \\
III & Akut hematojen enfeksiyon & Ameliyat sonrası $>4$ hafta, hematojen yol ile bulaş & $\begin{array}{l}\text { Debridman, protezin korunması ve } \\
\text { antibiyotik tedavisi, tedavi başarısız } \\
\text { olursa iki aşamalı revizyon }\end{array}$ \\
IV & Geç kronik enfeksiyon & Ameliyat sonrası $>4$ hafta, sinus ağzı mevcut & iki aşamalı değişim
\end{tabular}




\section{TEDAVI SEÇENEKLERI}

Total diz protezi sonrası gelişen enfeksiyonların tedavisi için birden çok tedavi yöntemi bulunmaktadır. Bu tedavi yöntemleri ${ }^{[27]}$;

- antibiyotikle baskılama,

- debridman, antibiyotik ve implantların korunması (DAIR),

- tek aşamalı değişim,

- iki aşamalı değişim,

- artrodez ve

- amputasyon olarak sayılabilir.

Tedavi planının belirlenmesinde enfeksiyonun ortaya çıkış zamanı, protezde gevşeme bulgusu, çevre yumuşak dokunun durumu, etken patojenin virülansı, kültür antibiyogram sonucu, hastanın genel sağlık durumu ve beklentisi oldukça önemlidir.

\section{Antibiyotikle Baskılama}

Eşlik eden hastalıklarından dolayı cerrahi yapılmasına izin verilemeyen veya cerrahi tedaviyi kabul etmeyen hastalarda ve etken organizmaya etkili yan tesirleri az olan antibiyotiğin verilebileceği durumlarda uygulanabilir. ${ }^{[24]}$

\section{Debridman, Antibiyotik ve İmplantların korunması (DAIR)}

Debridman, antibiyotik ve implantların korunması işlemi erken enfeksiyonlarda uygulanan debridman, antibiyotik tedavisi ve protezin korunarak sadece modüler komponentlerin değiştirildiği tedavi yöntemidir. Bu tedavi yönteminin endikasyonları ${ }^{[28]}$;

- protezin stabil olması,

- semptomların süresinin 4-6 haftayı geçmemesi,

- etken patojenin antibiyotiklere duyarlı olması,

- deri ve yumuşak doku örtüsünün sağlam olması,

- hastanın eşlik eden hastalıklarının az olması ve

- hastanın bağışıklık sisteminin güçlü olmasıdır.

Hasta seçimi uygun yapılmak kaydı ile DAIR prosedürü ile \%57 ile \%89 arasında başarı elde edilebilmektedir. ${ }^{[28]}$

\section{Tek Aşamalı Değişim}

Tek aşamalı değişim, cerrahinin tek aşamada tamamlanması, antibiyotik tedavisinin süresini kısaltması, hastanede kalış süresini kısaltması ve tedavi maliyetini düşürmesi gibi avantajlarından dolayı özellikle Avrupa ve Kuzey Amerika'da TDP sonrası enfeksiyon tedavisinde uygulanma sıklığı giderek artan bir yöntemdir. ${ }^{[27,29]}$
Enfeksiyona neden olan organizmanın tanımlanması ve onun antibiyotik duyarlılığının ameliyattan önce belirlenmesi ve yumuşak doku örtüsünün yeterli olması tek aşamalı değişim için gereklidir. ${ }^{[29]}$

Tek aşamalı revizyon kontrendikasyonları ${ }^{[29]}$;

- sepsis bulgularının olması,

- iki veya daha fazla tek aşamalı revizyon başarısızlık öyküsü,

- enfeksiyonun radikal debridmanı engelleyecek şekilde nörovasküler yapılara yayılması,

- uygun antibiyotik tedavisinin belirlenemediği kültür negatif enfeksiyon varlığı ve

- yumuşak doku örtüsünün implantın üzerini kapatmada yetersiz olmasıdır.

Ameliyat sırasında protez ve tüm yabancı cisimler çıkarılır ve radikal debridman yapılır. Rezeksiyon işlemi tamamlandıktan sonra aynı aşamada yeni steril malzemeler ile reimplantasyon yapılır. Sistemik antibiyotik tedavisi ameliyat sonrası $10-14$ gün uygulanır. ${ }^{[29,30]}$

\section{iki Aşamalı Değişim}

İki aşamalı değişim kronik TDP enfeksiyonlarında en sık tercih edilen tedavi yöntemidir. ${ }^{[27-31]}$ illk aşamada protez, çimento ve yabancı cisimlerin tümü çıkarılır. Enfekte ve nekrotik dokuların tamamı titiz bir şekilde debride edilir. Protez çevresindeki membranlardan, femur ve tibianın intramedüller alanlarından ve posterior kapsül çevresinden, 3-6 adet doku örneği kültür için alınır. İşlem boyunca basınçlı (pulsatil) yıkama yapılmalıdır. ${ }^{[29,32]}$ Ardından antibiyotikli boşluk doldurucu (speysır, spacer) uygulanır. Statik (harekete izin vermeyen) ve dinamik (harekete izin veren) olmak üzere iki tip antibiyotikli boşluk doldurucu vardır. Etken organizmaya etkili uygun dozda antibiyotik kullanılması önemlidir [29,31]

Birinci aşama tamamlandıktan sonra sistemik antibiyotik tedavisi başlanır. Antibiyotik verilme yolu ve süresi ile ilgili tam bir fikir birliği yoktur. ${ }^{[31]} 4-6$ hafta intravenöz antibiyotik tedavisi sonrasında mikroorganizmanın direnç profiline ve antibiyotik duyarlılığına göre oral antibiyotik tedavisine geçilebilir ${ }^{[29,31]}$

İkinci aşamanın zamanlamasının belirlenmesi için literatürdeki kanıtlar yeterli değildir. Yaranın klinik olarak iyi olması, CRP ve sedimentasyon değerlerinin düşme eğiliminde olması ve stabil olması durumunda genellikle 8-12 hafta sonra ikinci aşama planlanır. ${ }^{[29,33]}$ ikinci aşama öncesi eklem aspirasyonu yapılarak hücre sayımları ve lökosit esteraz testi yapılması önerilmektedir. İkinci aşama sırasında kültür için doku ve sıvı örnekleri alındıktan sonra yeniden etkili bir debridman ve basınçlı yıkama (pulsatil lavaj) yapılır. Daha sonra reimplantasyon 
yapılır. Re-implantasyon sonrası 3-6 ay süre ile antibiyotik tedavisinin yararlı olduğu bildirilmiştir ${ }^{[31]}$

\section{Artrodez}

Rekonstrüktif işlemlerin başarısız olduğu genç aktif hastalar ve çoklu dirençli patojenlerin neden olduğu tekrarlayıcı TDP enfeksiyonu olan hastalar artrodez için uygun hastalardır. ${ }^{[34]}$

\section{Amputasyon}

Amputasyon en son tedavi seçeneğidir. Hayatı tehdit eden sistemik sepsisi olan hastalarda tek tedavi seçeneği olabilir. Ayrıca yumuşak dokuların yoğun tutulumunun olduğu, artrodez yapılamayacak kadar büyük kemik kaybı olan ve enfeksiyon kontrolünde birçok başarısız girişimle birlikte inatçı enfeksiyonu devam eden hastalarda amputasyon tedavi seçeneği olarak düşünülmelidir. ${ }^{[29]}$

Sonuç olarak TDP sonrası gelişen enfeksiyon hastaya, hastanın ailesine, hekime, sağlık sistemine ve topluma maddi ve manevi olarak büyük yükler getiren en zor komplikasyonlardan biridir. Bu nedenle enfeksiyon riskini azaltmak için hastanın ameliyat öncesi hazırlığının yeterli ve özenli bir şekilde yapılması, ameliyathane şartlarının uygun olması, cerrahinin titiz yapılması, yumuşak doku hasarından kaçınılması, ameliyat sonrası erken dönemde gelişen yara sorunlarının etkili ve hızlı bir şekilde tedavi edilmesi çok önemlidir. Kaçınılmaz olarak bazı hastalarda enfeksiyon geliştiğinde ise vakit kaybetmeden tanının konması, hastanın yaşına, eşlik eden hastalıklarına, kemik kalitesine, yumuşak doku örtüsüne ve organizma tipine uygun, başarı olasılığı en yüksek olan tedavi yönteminin belirlenmesi, zamanında ve etkili bir şekilde uygulanması için gereken gayret muntazam bir şekilde gösterilmelidir.

\section{KAYNAKLAR}

1. Guo EW, Sayeed Z, Padela MT, Qazi M, Zekaj M, Schaefer $P$, Darwiche HF. Improving Total Joint Replacement with Continuous Quality Improvement Methods and Tools. Orthop Clin North Am 2018;49(4):397-403. Crossref

2. Yoshiya S, Kurosaka M, Kuroda R. Complications of total knee arthroplasty. Progress Clin Med JMAJ 2001;44(5):235-40. https://www.med.or.jp/english/pdf/2001_05/235_240.pdf

3. Feng B, Lin J, Jin J, Qian W-W, Wang W, Weng X-S. Thirtyday postoperative complications following primary total knee arthroplasty: A retrospective study of incidence and risk factors at a single center in China. Chin Med J (Engl) 2017;130(21):2551-56. Crossref

4. Kurtz S, Ong K, Lau E, Mowat F, Halpern M. Projections of primary and revision hip and knee arthroplasty in the United States from 2005 to 2030. J Bone Joint Surg Am 2007;89(4):780-85. Crossref

5. Del Pozo JL, Patel R. Clinical practice. Infection associated with prosthetic joints. N Engl J Med 2009;361(8):787-94. Crossref
6. Kurtz SM, Ong KL, Lau E, Bozic KJ, Berry D, Parvizi J. Prosthetic joint infection risk after TKA in the Medicare population. Clin Orthop Relat Res 2010;468(1):52-6. Crossref

7. Berbari EF, Hanssen AD, Duffy MC, Steckelberg JM, Ilstrup DM, Harmsen WS, Osmon DR. Risk factors for prosthetic joint infection: case control study. Clin Infect Dis 1998;27(5):1247-54. Crossref

8. Blanco JF, Díaz A, Melchor FR, da Casa C, Pescador D. Risk factors for periprosthetic joint infection after total knee arthroplasty. Arch Orthop Trauma Surg 2020;140(2):23945. Crossref

9. Stryker LS, Abdel MP, Morrey ME, Morrow MM, Kor DJ, Morrey BF. Elevated postoperative blood glucose and preoperative hemoglobin $\mathrm{A} 1 \mathrm{C}$ are associated with increased wound complications following total joint arthroplasty. J Bone Joint Surg Am 2013;95(9):808-14. Crossref

10. Capozzi JD, Lepkowsky ER, Callari MM, Jordan ET, Koenig JA, Sirounian GH. The Prevalence of Diabetes Mellitus and Routine Hemoglobin A1c Screening in Elective Total Joint Arthroplasty Patients. J Arthroplasty 2017;32(1):304-8. Crossref

11. Namba RS, Paxton L, Fithian DC, Stone ML. Obesity and perioperative morbidity in total hip and total knee arthroplasty patients. J Arthroplasty 2005;20(7 Suppl 3):4650. Crossref

12. Jauregui JJ, Kapadia BH, Dixit A, Naziri Q, Hip-Flores DJ, Harwin SF, Mont MA. Thirty-day complications in rheumatoid patients following total knee arthroplasty. Clin Rheumatol 2016;35(3):595-600. Crossref

13. Kadota Y, Nishida K, Hashizume K, Nasu Y, Nakahara R, Kanazawa T, Ozawa M, Harada R, Machida T, Ozaki T. Risk factors for surgical site infection and delayed wound healing after orthopedic surgery in rheumatoid arthritis patients. Mod Rheumatol 2016;26(1):68-74. Crossref

14. Simons MJ, Amin NH, Scuderi GR. Acute Wound Complications After Total Knee Arthroplasty: Prevention and Management. J Am Acad Orthop Surg 2017;25(8):547-55. Crossref

15. Greene KA, Wilde AH, Stulberg BN. Preoperative nutritional status of total joint patients. Relationship to postoperative wound complications. J Arthroplasty 1991;6(4):321-25. Crossref

16. Alamanda VK, Springer BD. Perioperative and Modifiable Risk Factors for Periprosthetic Joint Infections (PJI) and Recommended Guidelines. Curr Rev Musculoskelet Med 2018;11(3):325-31. Crossref

17. Vuorinen M, Mäkinen $T$, Rantasalo M, Leskinen J, Välimaa $H$, Huotari K. Incidence and risk factors for dental pathology in patients planned for elective total hip or knee arthroplasty. Scand J Surg 2019;108(4):338-42. Crossref

18. Maier GS, Horas K, Seeger JB, Roth KE, Kurth AA, Maus U. Is there an association between periprosthetic joint infection and low vitamin D levels? Int Orthop 2014;38(7):1499-504. Crossref

19. Arshi A, Shieh A, Adams JS, Bernthal NM, Zeegen EN, Sassoon AA. Preoperative Vitamin D Repletion in Total Knee Arthroplasty: A Cost-Effectiveness Model. J Arthroplasty 2020;35(5):1379-83. Crossref

20. Villa JM, Pannu TS, Riesgo AM, Patel PD, Mont MA, Higuera-Rueda CA. Dual Antibiotic Prophylaxis in Total Knee Arthroplasty: Where Do We Stand? J Knee Surg 2020;33(2):100-5. Crossref

21. Kheir MM, Tan TL, Azboy I, Tan DD, Parvizi J. Vancomycin Prophylaxis for Total Joint Arthroplasty: Incorrectly Dosed and Has a Higher Rate of Periprosthetic Infection Than Cefazolin. Clin Orthop Relat Res 2017;475(7):1767-74. Crossref 
22. Siljander MP, Sobh AH, Baker KC, Baker EA, Kaplan LM. Multidrug-Resistant Organisms in the Setting of Periprosthetic Joint Infection-Diagnosis, Prevention, and Treatment. J Arthroplasty 2018;33(1):185-94. Crossref

23. Parvizi J, Shohat N, Gehrke T. Prevention of periprosthetic joint infection: new guidelines. Bone Joint J 2017;99-B(4 Suppl B):3-10. Crossref

24. Li C, Renz N, Trampuz A, Ojeda-Thies C. Twenty common errors in the diagnosis and treatment of periprosthetic joint infection. Int Orthop 2020;44(1):3-14. Crossref

25. International Consensus Group (ICM). The Second International Consensus Meeting (ICM) on orthopaedic infections. https://icmphilly.com/general-assembly

26. Tsukayama DT, Goldberg VM, Kyle R. Diagnosis and management of infection after total knee arthroplasty. J Bone Joint Surg Am 2003;85-A(Suppl 1):75-80. Crossref

27. Leta TH, Lygre SHL, Schrama JC, Hallan G, Gjertsen JE, Dale $\mathrm{H}$, Furnes O. Outcome of Revision Surgery for Infection After Total Knee Arthroplasty: Results of 3 Surgical Strategies. JBJS Rev 2019;7(6):e4. Crossref

28. Jacobs AME, Valkering LJJ, Bénard M, Meis JF, Goosen JHM. Evaluation One Year after DAIR Treatment in 91 Suspected Early Prosthetic Joint Infections in Primary Knee and Hip Arthroplasty. J Bone Jt Infect 2019;4(5):238-44. Crossref
29. Gehrke T, Alijanipour P, Parvizi J. The management of an infected total knee arthroplasty. Bone Joint J 2015;97-B(10 Suppl A):20-9. Crossref

30. Pellegrini A, Meani E, Macchi V, Legnani C. One-stage revision surgery provides infection eradication and satisfying outcomes for infected knee arthroplasty in selected patients. Expert Rev Anti Infect Ther 2021;19(7):945-8. Crossref

31. Yang J, Parvizi J, Hansen EN, Culvern CN, Segreti JC, Tan T, Hartman CW, Sporer SM, Della Valle CJ; The Knee Society Research Group. 2020 Mark Coventry Award: Microorganism-directed oral antibiotics reduce the rate of failure due to further infection after two-stage revision hip or knee arthroplasty for chronic infection: a multicentre randomized controlled trial at a minimum of two years. Bone Joint J 2020;102-B(6 Suppl A):3-9. Crossref

32. Xu C, Goswami K, Li WT, Tan TL, Yayac M, Wang S-H, Parvizi J. Is Treatment of Periprosthetic Joint Infection Improving Over Time? J Arthroplasty 2020;35(6):1696-702.e1. Crossref

33. Kusuma SK, Ward J, Jacofsky M, Sporer SM, Della Valle CJ. What is the role of serological testing between stages of twostage reconstruction of the infected prosthetic knee? Clin Orthop Relat Res 2011;469(4):1002-8. Crossref

34. Conway JD. Knee Arthrodesis for Recurrent Periprosthetic Knee Infection. JBJS Essent Surg Tech 2020;10(3):e19.00027. Crossref 